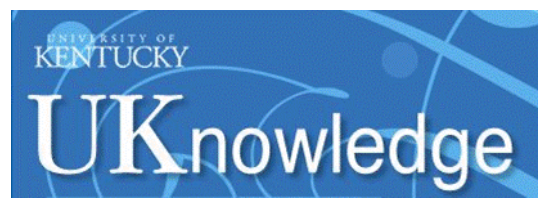

University of Kentucky

UKnowledge

\title{
Effects of Allergen Sensitization on Response to Therapy in Children with Eosinophilic Esophagitis
}

\author{
Robert D. Pesek \\ Arkansas Children's Hospital \\ Mallikarjuna Rettiganti \\ Arkansas Children's Hospital \\ Erin O'Brien \\ Arkansas Children's Hospital \\ Sarah Beckwith \\ Arkansas Children's Hospital \\ Caroline Daniel \\ Arkansas Children's Hospital
}

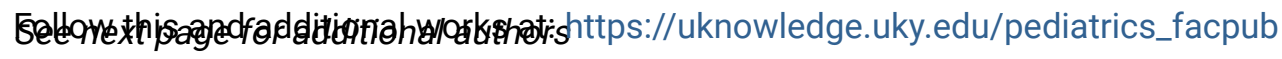

Part of the Allergy and Immunology Commons, and the Pediatrics Commons

Right click to open a feedback form in a new tab to let us know how this document benefits you.

\section{Repository Citation}

Pesek, Robert D.; Rettiganti, Mallikarjuna; O'Brien, Erin; Beckwith, Sarah; Daniel, Caroline; Luo, Chunqiao; Scurlock, Amy M.; Chandler, Peggy; Levy, Rebecca A; Perry, Tamara T.; Kennedy, Joshua L.; Chervinskiy, Sheva; Vonlanthen, Maryelle; Casteel, Helen; Fiedorek, Stephen C.; Gibbons, Troy; and Jones, Stacie M., "Effects of Allergen Sensitization on Response to Therapy in Children with Eosinophilic Esophagitis" (2017). Pediatrics Faculty Publications. 296.

https://uknowledge.uky.edu/pediatrics_facpub/296

This Article is brought to you for free and open access by the Pediatrics at UKnowledge. It has been accepted for inclusion in Pediatrics Faculty Publications by an authorized administrator of UKnowledge. For more information, please contact UKnowledge@lsv.uky.edu. 


\section{Effects of Allergen Sensitization on Response to Therapy in Children with Eosinophilic Esophagitis}

\section{Digital Object Identifier (DOI)}

https://doi.org/10.1016/j.anai.2017.06.006

\section{Notes/Citation Information}

Published in Annals of Allergy, Asthma \& Immunology, v. 119, issue 2, p. 177-183.

(c) 2017 American College of Allergy, Asthma \& Immunology. Published by Elsevier Inc. All rights reserved.

This manuscript version is made available under the CC-BY-NC-ND 4.0 license

https://creativecommons.org/licenses/by-nc-nd/4.0/.

The document available for download is the author's post-peer-review final draft of the article.

\section{Authors}

Robert D. Pesek, Mallikarjuna Rettiganti, Erin O'Brien, Sarah Beckwith, Caroline Daniel, Chunqiao Luo, Amy M. Scurlock, Peggy Chandler, Rebecca A Levy, Tamara T. Perry, Joshua L. Kennedy, Sheva Chervinskiy, Maryelle Vonlanthen, Helen Casteel, Stephen C. Fiedorek, Troy Gibbons, and Stacie M. Jones 


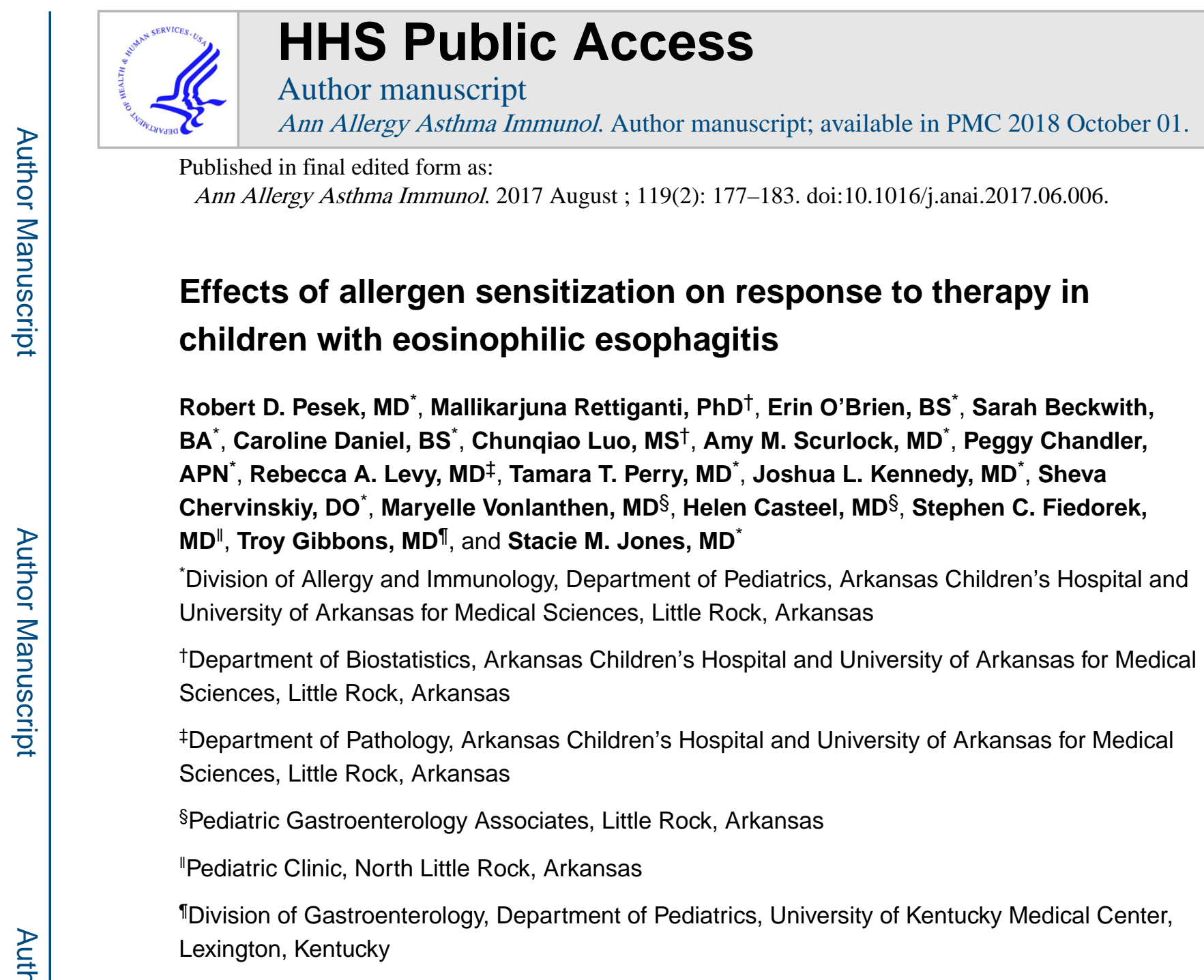

\section{Abstract}

Background: In children with eosinophilic esophagitis (EoE) foods are the most common disease triggers, but environmental allergens are also suspected culprits.

Objective: To determine the effects of environmental allergen sensitization on response to treatment in children with EoE in the southeastern United States.

Methods: Patients 2 to 18 years old who were referred to the Arkansas Children's Hospital Eosinophilic Gastrointestinal Disorders Clinic from January 2012 to January 2016 were enrolled in a prospective, longitudinal cohort study with collection of demographics, clinical symptoms, medical history, allergy sensitization profiles, and response to treatment over time. Comparisons were made between complete responders (peak esophageal eosinophil count $<15$ per high-power field [HPF]) and nonresponders ( $>25$ eosinophils per HPF) after treatment with diet elimination alone, swallowed corticosteroids alone, or diet elimination and swallowed corticosteroids. Sensitization patterns to environmental allergens found in the southeastern United States were analyzed for the effect on treatment response.

Reprints: Robert D. Pesek, MD, Division of Allergy/Immunology, Arkansas Children's Hospital, 13 Children's Way, Slot 512-13, Little Rock, AR 72202; rdpesek@uams.edu.

Disclosures: Dr Jones reported serving as a research advisory board member for Food Allergy Research and Education. 
Results: A total of 223 individuals were enrolled. Of these, 182 had environmental allergy profiling and at least one endoscopy while receiving proton pump inhibitor (PPI) therapy. Twentynine individuals had PPI-responsive EoE and were excluded from further analysis, leaving 123 individuals with none-PPI-responsive EoE who were further analyzed; 72 (58.5\%) were complete responders and $33(26.8 \%)$ were nonresponders. Seventeen individuals (13.8\%) were partial responders ( $\geq 1$ but $\leq 25$ eosinophils per HPF) and excluded from further analysis. Nonresponders were more likely to be sensitized to perennial allergens $(\mathrm{P}=.02)$. There was no significant difference in response based on seasonal allergen sensitization. Individuals with mold or cockroach sensitization were more likely to fail combination diet and swallowed corticosteroid treatment $(\mathrm{P}=.02$ and $\mathrm{P}=.002)$.

Conclusion: Perennial allergen and mold sensitization may lead to nonresponse to EoE treatment in some patients. Additional studies are needed to further understand the effect of environmental allergens on EoE.

Trial Registration: http://ClinicalTrials.gov identifier: NCT01779154.

\section{Introduction}

Eosinophilic esophagitis (EoE) is an increasing clinical problem. Estimates of prevalence in the United States have increased from 2.3 per 100,000 population in 1976 to 25.9 per 100,000 population in 2015 , with even higher rates reported in some populations. ${ }^{1-4}$ Characterized by eosinophilic inflammation of the esophagus, affected patients may experience a variety of clinical symptoms that lead to increased health care use and decreased quality of life. ${ }^{5}$ Diagnostic options are limited to repetitive endoscopy, whereas treatment is centered on use of swallowed corticosteroids or diet restrictions. Although food remains the most common trigger, ${ }^{6,7}$ the role of aeroallergens in the development of EoE has also been questioned. Several studies have found changing clinical symptoms during peak pollen seasons, especially in those with concomitant allergic rhinitis. ${ }^{8-10}$ The frequency of diagnosis also appears to increase during pollen seasons, with a lower frequency found in winter. ${ }^{1-14}$ However, other studies have found no clear link among aeroallergen sensitization, symptom onset, and seasonal diagnosis of EoE..$^{15-18}$

Most EoE studies have been completed in urban populations. It is unclear whether there are differences in disease presentation and response to management in rural or other nonurban populations. ${ }^{16,18-20}$ As such, characterization of different patient populations is important to obtain a clearer understanding of the disease process and to optimize management strategies. In 2015, $42 \%$ of Arkansas' population lived in nonurban areas vs $15 \%$ for the US population as a whole. This nonurban population has not been described compared with those living in other environments. ${ }^{21}$ The purpose of this study was to determine the effects of seasonal and perennial allergen sensitization on the response to treatment in a pediatric population with EoE living in the southeastern region of the United States. 


\section{Methods}

\section{Patient Inclusion}

Patients 2 to 18 years of age who were referred to the Arkansas Children's Hospital multispecialty Eosinophilic Gastrointestinal Disorders Clinic from January 2012 to January 2016 were considered for enrollment. Patients were required to have had at least one esophageal endoscopy with findings of 15 eosinophils per high-power field (HPF) or more at $40 \times$ magnification on at least one esophageal biopsy specimen as reviewed by a boardcertified pathologist (R.A.L.). Patients were then consented and enrolled in a prospective, longitudinal cohort with collection of data, including demographics, clinical symptoms, medical, family, and diet history, allergy profiles, and response to treatment over time. The study was approved by the University of Arkansas for Medical Sciences Institutional Review Board. Written consent was obtained from each study participant.

\section{Allergy Profiling}

Environmental allergen sensitization was determined through use of skin prick testing (SPT) and/or serum specific IgE testing (ImmunoCAP, Phadia AB, Uppsala, Sweden). SPT was performed using the Greer Pick Single Site Allergy Skin Test System (Greer Labs, Lenoir, North Carolina) with histamine and saline controls. Testing to perennial allergens included dust mites (Dermatophagoides pteronyssinus and Dermatophagoides farinae), cat hair (Felis catus domesticus), dog epithelia (Canis species), cockroach (Periplaneta americana), and mold (Aspergillus, Alternaria, Cladosporium, and Curvularia). Seasonal allergens included trees (elm, white ash, eastern oak, hickory/pecan, black walnut, birch, mountain cedar, and cottonwood), grasses (Bermuda, Bahia, fescue, Johnson, and timothy), and weeds (ragweed, pigweed, dock/sorrel, marsh elder, plantain, and hemp) found throughout the southeast region of the United States. Individual test results were considered positive if the individuals had a SPT wheal size of $3 \mathrm{~mm}$ or larger than the negative control and/or a serum specific IgE level of $0.35 \mathrm{kU} / \mathrm{L}$ or higher. Allergy testing was performed at the initial EoE visit to the standard panel of environmental allergens in all patients unless declined by the patient or family. Previous allergy testing completed during the 2 years before visit or enrollment was also accepted. For most patients, allergy testing was performed before the initiation of EoE treatment. Allergy testing performed after initiation of EoE treatment was also accepted. Responses to management were compared between patients with seasonal, perennial, and/or mold sensitization and those with no sensitization.

\section{Response to Treatment}

Response to treatment, including response to proton pump inhibitors (PPI), dietary manipulation, and/or use of swallowed corticosteroids, was assessed. All patients were assigned to at least 8 weeks of PPI therapy with follow-up endoscopy to assess PPI responsiveness. Dosing of PPI was based on physician preference. For those in whom PPI treatment failed, management decisions were based on physician and parental preference using diet elimination alone, swallowed corticosteroids alone, or a combination of both diet elimination and swallowed corticosteroids. If diet manipulation was chosen, the patient was placed on allergenspecific elimination (single allergen elimination or combination allergen elimination based on allergy testing and clinical history), 6-food elimination (milk, egg, soy, 
wheat, peanut or tree nuts, fish or shellfish), or elemental diet using an elemental formula alone. Patients then received one-on-one dietary counseling provided by a trained dietician. If swallowed corticosteroids were choses, the patients were given budesonide (dosing range, $0.25-1 \mathrm{mg}$ twice daily) or fluticasone propionate (220-880 $\mu$ g twice daily). If budesonide was used, patients were instructed to mix each $2-\mathrm{mL}$ respule with 4 packets of a sugar substitute (Splenda). If fluticasone propionate was chosen, patients were instructed to spray the inhaler directly into the mouth and swallow. Patients were also instructed to avoid eating or drinking for 30 minutes after taking the medication.

Patients continued to receive treatment for at least 10 to 12 weeks before additional endoscopy was performed. Patients were considered complete responders if the peak esophageal eosinophil count was less than 15 eosinophils per HPF and nonresponders if the peak esophageal eosinophil count was greater than 25 eosinophils per HPF. Patients with peak eosinophil counts greater than 15 eosinophils per HPF but less than 25 eosinophils per HPF were considered partial responders but were excluded from further analysis. Symptom improvement was not used as a measure of response to treatment.

\section{Statistical Analysis}

All demographics and clinical outcomes were summarized using mean (SD) for continuous variables and frequency (percentage) for categorical variables. Categorical variables in 2 independent groups were compared using a Fisher exact test. Continuous variables in 2 independent groups were compared using the Wilcoxon rank-sum test. Paired categorical outcomes with more than 2 categories were compared using the Bowker test of symmetry. Effects for dichotomous outcomes were summarized using odds ratios (ORs) and 95\% confidence intervals (CIs). All tests conducted were 2-sided, assuming a significance level of 5\%. All statistical analyses were performed using the software R, version 3.0.2. Descriptive tables were generated using the Regression Modeling Strategies package.

\section{Results}

\section{Study Population}

A total of 223 patients were enrolled in the study (Fig 1). Of these, 182 patients had allergy profiling to food and environmental allergens and at least one endoscopy while receiving PPI therapy. Commonly used PPIs included omeprazole (dose range, 8-40 mg; median, $20 \mathrm{mg}$ ), lansoprazole (dose range, 10-40 mg; median, $20 \mathrm{mg}$ ), and esomeprazole (dose range, 20-40 $\mathrm{mg}$; median, $40 \mathrm{mg}$ ). One patient was excluded from further analysis because there were no results available from the follow-up endoscopy and no further endoscopies were performed. Twenty-nine patients (15.9\%) were considered to have PPI-responsive EoE vs gastroesophageal reflux and were also excluded from further analysis. Of the 152 patients with none-PPI-responsive EoE, 29 did not have a follow-up endoscopy and were excluded from further analysis. A total of 123 patients with none-PPI-responsive EoE had at least one follow-up endoscopy and were analyzed for demographics, medical history, clinical symptoms, allergen sensitization, and response to management. 


\section{Demographic and Clinical Symptoms}

The mean (SD) age at diagnosis was 7.6 (4.88) years with $69 \%$ male patients, $86.1 \%$ white patients, and 9\% African American patients (Table 1). Predominant insurance types included both Medicaid (44.7\%) and private (38.2\%), and $41 \%$ of patients lived in nonurban counties ( $<65,000$ residents). Patients underwent a mean of 3 endoscopies. ${ }^{3,5}$ Patients were more likely to have their conditions diagnosed during the months of July and August and least likely to have their conditions diagnosed during September, October, and November, although this finding was not statistically significant (Fig 2). Patients had a high incidence of atopic disorders (73.2\%), including allergic rhinitis (52.8\%), asthma (43.1\%), food allergy (36.6\%), and atopic dermatitis (26.8\%). More than $40 \%$ of patients had a history of gastroesophageal reflux. Less than $1 \%$ of patients had a prior diagnosis of celiac disease. Heartburn or food regurgitation (71.2\%), nausea or vomiting (67.3\%), abdominal pain(55.8\%), and dysphagia (50\%) were the most common reported symptoms in all age groups. Although the occurrence of dysphagia was similar across age groups, food impaction (overall, 11.8\%) increased with age and occurred most commonly in patients who were 12 years or older $(40 \%)$.

\section{Allergen Profiles}

Environmental allergen profiling was completed in a total of 123 patients as previously described. Approximately $50 \%$ of patients were sensitized to seasonal and perennial allergens. Trees were the most common seasonal allergen (44.7\%) followed by grasses (42.2\%), and weeds (39.8\%) (Table 2). Dust mites were the most common sensitized perennial allergen $(34.1 \%)$ followed by cat $(29.3 \%)$ and dog $(17.9 \%)$ dander. Nearly $30 \%$ of patients were sensitized to molds. Sensitization to seasonal and perennial allergens increased with age, occurring in $43.5 \%$ (seasonal) and $50 \%$ (perennial) of patients 5 years or younger and $69 \%$ (seasonal) and 76\% (perennial) patients 12 years or older. A similar pattern was seen with mold sensitization.

\section{Response to Management}

Response to management was assessed in 123 patients with none-PPI-responsive EoE. Of those, 72 (58.5\%) were complete responders (peak eosinophil count $<15$ eosinophils per HPF), and 33 (26.8\%) were nonresponders (peak eosinophil count >25 per HPF). Seventeen patients (13.8\%) were partial responders (peak eosinophil count $\geq 15$ but $\_25$ eosinophils per HPF). For all responder groups, there was a decrease in mean (SD) peak eosinophil count during the study period: complete responders, 56.2 (39.7) to 2.3 (3.0) eosinophils per HPF (92.5\% reduction); partial responders, 57.2 (24.7) to 20.1 (3.7) eosinophils per HPF (57.3\% reduction); and nonresponders, 81.2 (25.2) to 59.4 (24.4) eosinophils per HPF (17.1\% reduction). In complete responders, 32 patients (44.4\%) were managed with diet elimination alone, 21 patients $(29.2 \%)$ with swallowed corticosteroids alone, and 18 patients $(25 \%)$ with both diet elimination and swallowed corticosteroids. One complete responder did not implement any management but had clearance of esophageal eosinophils on subsequent endoscopy. In nonresponders, 19 patients $(57.6 \%)$ were managed with diet elimination alone, 2 patients $(6.1 \%)$ with swallowed corticosteroids alone, and 12 patients $(36.3 \%)$ with both diet elimination and swallowed corticosteroids. One nonresponder did not implement 
any management during the study period and was excluded from analysis. There were no significant differences between complete and nonresponders in regard to sex, race, insurance type, or county of residence (urban vs nonurban). The most commonly used diet across responder groups was allergen-specific food elimination followed by 6-food elimination (Table 3). Budesonide was the most commonly used swallowed corticosteroid (daily dosing range, $0.5-2 \mathrm{mg}$; mean, $1 \mathrm{mg}$ ) followed by fluticasone propionate (daily dosing range, 220$1760 \mu \mathrm{g}$; mean, $880 \mu \mathrm{g}$ ). When comparing management by age group, children 6 to 11 years old and 12 years or older were more likely to be treated with swallowed corticosteroids or corticosteroids plus diet elimination, but this difference was not statistically significant $(\mathrm{P}=$. 051).

\section{Effect of Allergen Sensitization on Response to Management}

Patients were compared by management response status (complete responders vs nonresponders) and allergy testing results (positive vs negative SPT or IgE test results) to assess the effects of perennial, mold, and seasonal allergen sensitization on treatment response. When comparing complete responders and nonresponders, nonresponders were more likely to be sensitized to perennial allergens $(\mathrm{P}=.02)$. Patients sensitized to molds were also more likely to be nonresponders, although this trend did not reach statistical significance. Patients were also analyzed based on the number of allergen groups (ie, dust mites, cat, dog, cockroach, molds, trees, grasses, or weeds) that they were sensitized to, but no significant differences in response status were found (Table 2). When assessing response by age and sensitization pattern, no differences were seen in patients younger than 5 years or 12 years or older, but patients 6 through 11 years of age were more likely to be nonresponders if they had perennial allergen sensitization $(\mathrm{P}=.02)$. Overall, no significant differences were found in the frequency of nonresponsiveness with increasing age (Table 4). There were no significant differences in the response statuses based on age and seasonal allergen sensitization.

When individual allergens were analyzed and evaluated for effects on response status, no significant difference was found in patients sensitized to dust mites or pet dander.

Sensitization to cockroach and molds had an effect on response status; in patients who underwent combination treatment with both diet elimination and swallowed corticosteroids, cockroach or mold sensitization was associated with a higher risk of nonresponse $(\mathrm{P}=.002$ and $\mathrm{P}=.02$, respectively) (Table 5).

\section{Discussion}

In this study, we analyzed the effect of seasonal and perennial allergen sensitization on the response to treatment in a pediatric population with EoE living in the southeastern region of the United States. Our results indicate that perennial allergen and mold sensitization can affect the response to therapy and may increase the risk of nonresponse in certain groups. Our population had similar clinical characteristics as reported in other regions, including a high rate of atopy and allergen sensitization, suggesting that patients may present similarly regardless of geographic location. ${ }^{17,19,22-24}$ There were also no differences found between patients living in rural vs nonrural counties. The most common clinical symptoms included 
vomiting, abdominal pain, and heart-burn, with older patients having a higher incidence of dysphagia and food impaction. Allergen profiling revealed a high rate of both seasonal and perennial allergen sensitization, which increased with age.

The role of environmental allergens in EoE has been suggested in multiple studies, with evidence of increased diagnosis during peak pollen seasons and worsening clinical symptoms. ${ }^{8-13}$ In the mouse model, delivery of aeroallergens intranasally promotes development of eosinophilic inflammation in the esophagus. This effect was not seen if aeroallergens were delivered via oral or gastric routes, suggesting that inhalation of aeroallergens can promote development of EoE. ${ }^{24}$ Much of the work thus far has been performed in adult populations, which generally show a higher rate of aeroallergen sensitization compared with children. Several studies performed in pediatric populations have failed to demonstrate an effect of aeroallergens on EoE diagnosis or clinical symptoms. $15-17$

Perennial allergens have not been as closely investigated, and because levels may not vary during different seasons of the year, their effect on EoE may be more difficult to examine. Molds can act as seasonal and perennial allergens, depending on the type of mold and environment under consideration. Levels can vary with seasonal changes, but indoor mold levels may be more constant throughout the year. Sensitization to molds and perennial allergens can be exhibited early in life and is associated with an increased risk of developing other atopic disorders, including asthma. ${ }^{25-28}$ In sensitized patients, these allergens can also serve as triggers for exacerbation of existing atopic diseases. Given that many children with EoE have coexisting atopic disorders, it would not be surprising to find that these allergens may exacerbate EoE.

Although our study did not find a significant effect from seasonal allergens on treatment response, perennial allergen sensitization increased the risk of nonresponse to management in several groups. This effect was most prevalent in patients 6 through 11 years of age and in those sensitized to cockroach and mold who were treated with diet elimination and swallowed corticosteroids. This result was not seen in patients 12 years or older, the group with the highest environmental allergen sensitization, which may be attributable to the small size of the group 12 years or older. These findings suggest that perennial and mold sensitization should be determined because there may be an effect on response to treatment, at least in some patient groups.

The utility of allergy testing in EoE has been questioned because the underlying mechanism does not appear to be IgE mediated. ${ }^{29,30}$ Although the positive predictive value of allergy testing in EoE to foods remains low (44\%-47\%), skin testing and serum specific IgE testing to environmental allergens is higher and more predictive of developing allergic disease in children. ${ }^{31-34}$ Given the correlation shown in our study between sensitization to perennial allergens and mold and poor response to management, allergy testing to environmental allergens in EoE should be considered. A similar recommendation was made by Olsen et $\mathrm{al}^{35}$ in their study of 257 adults with EoE. In their retrospective analysis, adults with aeroallergen sensitization were more likely to present with strictures than those who were not sensitized. In addition, several case reports have found improvement in the number of 
esophageal eosinophils seen in patients with EoE treated for environmental allergens, including birch pollen and dust mites, and in each of these cases, the patients had positive skin test results to the culprit allergen. ${ }^{36,37}$

Our study has several limitations. Approximately $18 \%$ of patients were excluded from treatment response analysis because of a lack of complete SPT or specific IgE testing to environmental allergens, which may have decreased the ability to detect differences in response to management. In addition, patients were assigned to a treatment plan based on practitioner experience and/or patient preference rather than an algorithm-based approach, which may have also decreased the potential response rate. PPI therapy may have also been discontinued during the study period. If a patient with EoE also had concomitant gastroesophageal reflux, discontinuation of the PPI therapy could have led to nonresponse to EoE treatment. None of the nonresponders were placed on an elemental diet; thus, it is possible that more patients could have achieved at least a partial response if this diet were implemented. A formal assessment for adherence with the recommended treatment plan was not performed; thus, patient adherence may have also affected the results. In regard to the effects of seasonal allergens, endoscopies were not performed based on time or season of the year but were performed after management changes. As a result, the effect of seasonal allergens on treatment response could have been missed.

Importantly, this is one of the first reports to suggest that sensitization to perennial and mold allergens may affect response to therapy in some patients with EoE. Although there were several confounding variables, certain patient groups sensitized to mold and/or perennial allergens were more likely to be nonresponders. Although use of diet elimination and/or swallowed corticosteroids remains the mainstay of treatment in EoE, consideration should be given to the pattern of environmental allergen sensitization because it could identify a phenotype of patient who may respond differently to management. Such patients may need to implement avoidance measures in their home environment to reduce exposure to these allergens. There may be benefit from allergen specific immunotherapy, although more work is needed to assess the effectiveness of this treatment in EoE. Additional studies are needed to determine whether the effects of perennial and mold sensitization on treatment response exists in other populations outside the southeast region of the United States.

\section{Acknowledgment}

We thank the Claudia and Steve Strange Family Fund for their generous financial support of the Arkansas Children's Hospital Eosinophilic Gastrointestinal Disorders Program.

Funding Sources: Support for this project was provided through research training grant U54 AI117804 as part of the Consortium of Eosinophilic Gastrointestinal Researchers. The Consortium of Eosinophilic Gastrointestinal Researchers is part of the Rare Disease Clinical Research Network, an initiative of the Office of Rare Diseases Research, National Center for Advancing Translational Sciences, and is funded through collaboration between National Institute of Allergy and Infectious Diseases, National Institute of Diabetes and Digestive and Kidney Diseases, and National Center for Advancing Translational Sciences.

\section{References}

[1]. Straumann A, Simon HU. Eosinophilic esophagitis: escalating epidemiology? J Allergy Clin Immunol. 2005;115:418-419. [PubMed: 15696105] 
[2]. Dellon ES, Jensen ET, Martin CF, Shaheen NJ, Kappelman MD. Prevalence of eosinophilic esophagitis in the United States. Clin Gastroenterol Hepatol. 2014; 12:589-596. [PubMed: 24035773]

[3]. Spergel JM, Book WM, Mays E, et al. Variation in prevalence, diagnostic criteria, and initial management options for eosinophilic gastrointestinal diseases in the United States. J Pediatr Gastroenterol Nutr. 2011;52: 300-306. [PubMed: 21057327]

[4]. Mansoor E, Cooper GS. The 2010-2015 prevalence of eosinophilic esophagitis in the USA: a population-based study. Dig Dis Sci. 2016;61:2928-2934. [PubMed: 27250980]

[5]. Dellon ES, Gonsalves N, Hirano I, et al. ACG Clinical Guideline: evidence based approach to the diagnosis and management of esophageal eosinophilia and eosinophilic esophagitis (EoE). Am J Gastroenterol. 2013;108:679-692. [PubMed: 23567357]

[6]. Kagalwalla AF, Shah A, Li BU, et al. Identification of specific foods responsible for inflammation in children with eosinophilic esophagitis successfully treated with empiric elimination diet. J Pediatr Gastroenterol Nutr. 2011;53: 145-149. [PubMed: 21788754]

[7]. Kagawalla AF, Sentongo TA, Ritz S, et al. Effect of six-food elimination diet on clinical and histological outcomes in eosinophilic esophagitis. Clin Gastroenterol Hepatol. 2006;4:10921102.

[8]. Philpott HL, Nadurkar S, Thien F, et al. Seasonal recurrence of food bolus obstruction in eosinophilic esophagitis. Intern Med J. 2015;45:939-943. [PubMed: 25871330]

[9]. Wolf WA, Jerath MR, Dellon ES. De-novo onset of eosinophilic esophagitis after large volume allergen exposure. J Gastrointest Liver Dis. 2013;22:205-208.

[10]. Larsson H, Bergquist H, Bove M. The incidence of esophageal bolus impaction: is there a seasonal variation? Otolaryngol Head Neck Surg. 2011;144:186-190. [PubMed: 21493413]

[11]. Jensen ET, Shah ND, Hoffman K, Sonnenberg A, Genta RM, Dellon ES. Seasonal variation in detection of oesophageal eosinophilia and eosinophilic oesophagitis. Aliment Pharmacol Ther. 2015;42:461-469. [PubMed: 26059636]

[12]. Ram G, Lee J, Ott M, et al. Seasonal exacerbation of esophageal eosinophilia in children with eosinophilic esophagitis and allergic rhinitis. Ann Allergy Asthma Immunol. 2015;115:224-228. [PubMed: 26235409]

[13]. Fogg MI, Ruchelli E, Spergel JM. Pollen and eosinophilic esophagitis. J Allergy Clin Immunol. 2003;112:796-797. [PubMed: 14564365]

[14]. Wang FY, Gupta SK, Fitzgerald JF. Is there a seasonal variation in the incidence or intensity of allergic eosinophilic esophagitis in newly diagnosed children? J Clin Gastroenterol.

2007;41:451-453. [PubMed: 17450024]

[15]. Schlegel CR, Quintanilla NM, Olive AP, Minard CG, Davis CM. Relationship of pediatric eosinophilic esophagitis diagnosis to pollen and mold counts. Ann Allergy Asthma Immunol. 2014;113:321-322. [PubMed: 24996994]

[16]. Elitsur Y, Aswani R, Lund V, Dementieva Y. Seasonal distribution and eosinophilic esophagitis: the experience in children living in rural communities. J Clin Gastroenterol. 2013;47:287-288. [PubMed: 23164688]

[17]. Sorser SA, Barawi M, Hagglund K, Almojaned M, Lyons H. Eosinophilic esophagitis in children and adolescents: epidemiology, clinical presentation and seasonal variation. J Gastroenterol. 2013;48:81-85. [PubMed: 22618806]

[18]. Gill R, Durst P, Rewalt M, Elitsur Y. Eosinophilic esophagitis disease in children from West Virginia: a review of the last decade (1995-2004). Am J Gastroenterol. 2007;102:2281-2285. [PubMed: 17573789]

[19]. Lee YJ, Redd M, Bayman L, Frederickson N, Valestin J, Schey V. Comparison of clinical features in patients with eosinophilic esophagitis living in an urban and rural environment. Dis Esophagus. 2015;28:19-24. [PubMed: 24382218]

[20]. Jensen ET, Hoffman K, Shaheen NJ, Genta RM, Dellon ES. Esophageal eosinophilia is increased in rural areas with low population density: results from a national pathology database. Am J Gastroenterol. 2014;109:668-675. [PubMed: 24667575]

[21]. University of Arkansas Division of Agriculture. Social and Demographic Reports on Rural Arkansas: Rural Profile of Arkansas 2015, https://www.uaex.edu/publications/pdf/MP-531.pdf. 
[22]. Rezende ER, Barros CP, Ynoue LH, Santos AT, Pinto RM, Sequndo GR. Clinical characterisitics and sensitivity to food and inhalants among children with eosinophilic esophagitis. BMC Res Notes. 2014;7:47. [PubMed: 24443803]

[23]. Liacouras CA, Spergel JM, Ruchelli E, et al. Eosinophilic esophagitis: a 10-year experience in 381 children. Clin Gastroenterol Hepatol. 2005;3:1198-1206. [PubMed: 16361045]

[24]. Mishra A, Hogan SP, Brandt EB, Rothenberg ME. An etiological role for aeroallergens and eosinophils in experimental esophagitis. J Clin Invest. 2001;107: 83-90. [PubMed: 11134183]

[25]. Arshad SH, Tariq SM, Matthews S, Hakim E. Sensitization to common allergens and its association with allergic disorders at age 4 years: a whole population birth cohort study. Pediatrics. 2001;108:E33. [PubMed: 11483843]

[26]. Boulet LP, Turcotte H, Laprise C, et al. Comparative degree and type of sensitization to common indoor and outdoor allergens in subjects with allergic rhinitis and/or asthma. Clin Exp Allergy. 1997;27: 52-59. [PubMed: 9117881]

[27]. Ro AD, Simpson MR, Storro O, Johnsen R, Videm V, Oien T. The predictive value of allergen skin prick tests and IgE tests at pre-school age: the PACT study. Pediatr Allergy Immunol. 2014;25:691-698. [PubMed: 25298031]

[28]. Droste JH, Kerhof M, de Monchy JG, Schouten JP, Rijcken B; The Dutch ECRHS Group. Association of skin test reactivity, specific IgE, total IgE, and eosinophils with nasal symptoms in a community based population study. J Allergy Clin Immunol. 1996;97:922-932. [PubMed: 8655887]

[29]. Mishra A, Schlotman J, Wang M, Rothenberg ME. Critical role for adaptive T cell immunity in experimental eosinophilic esophagitis in mice. J Leukoc Biol. 2007;81:916-924. [PubMed: 17194734]

[30]. Lucendo AJ, Bellon T, Lucendo B. The role of mast cells in eosinophilic esophagitis. Pediatr Allergy Immunol. 2009;20:512-518. [PubMed: 18681944]

[31]. Henderson CJ, Abonia JP, King EC, et al. Comparative dietary therapy effectiveness in remission of pediatric eosinophilic esophagitis. J Allergy Clin Immunol. 2012;129:1570-1578. [PubMed: 22541246]

[32]. Spergel JM, Brown-Whitehorn TF, Cianferoni A, et al. Identification of causative foods in children with eosinophilic esophagitis treated with an elimination diet. J Allergy Clin Immunol. 2012;130:461-467. [PubMed: 22743304]

[33]. McCann WA, Ownby DR. The reproducibility of the allergy skin test scoring and interpretation by board-certified/board-eligible allergists. Ann All Asthma Immunol. 2002;89:368-371.

[34]. Vanto T Efficacy of different skin test methods in diagnosis of allergy to dogs. Ann Allergy. 1982;49:340.

[35]. Olsen AA, Evans MD, Johansson MW, et al. Role of food and aeroallergen sensitization in eosinophilic esophagitis in adults. Ann Allergy Asthma Immunol. 2016;117:387-393. [PubMed: 27590636]

[36]. Ramirez RM, Jacobs RL. Eosinophilic esophagitis treated with immunotherapy to dust mites. J Allergy Clin Immunol. 2013;132:503-504. [PubMed: 23763975]

[37]. De Swert L, Veereman G, Bublin M, et al. Eosinophilic gastrointestinal disease suggestive of pathogenesis-related class 10 (PR-10) protein allergy resolved after immunotherapy. J Allergy Clin Immunol. 2013;131: 600-602. [PubMed: 23374273] 


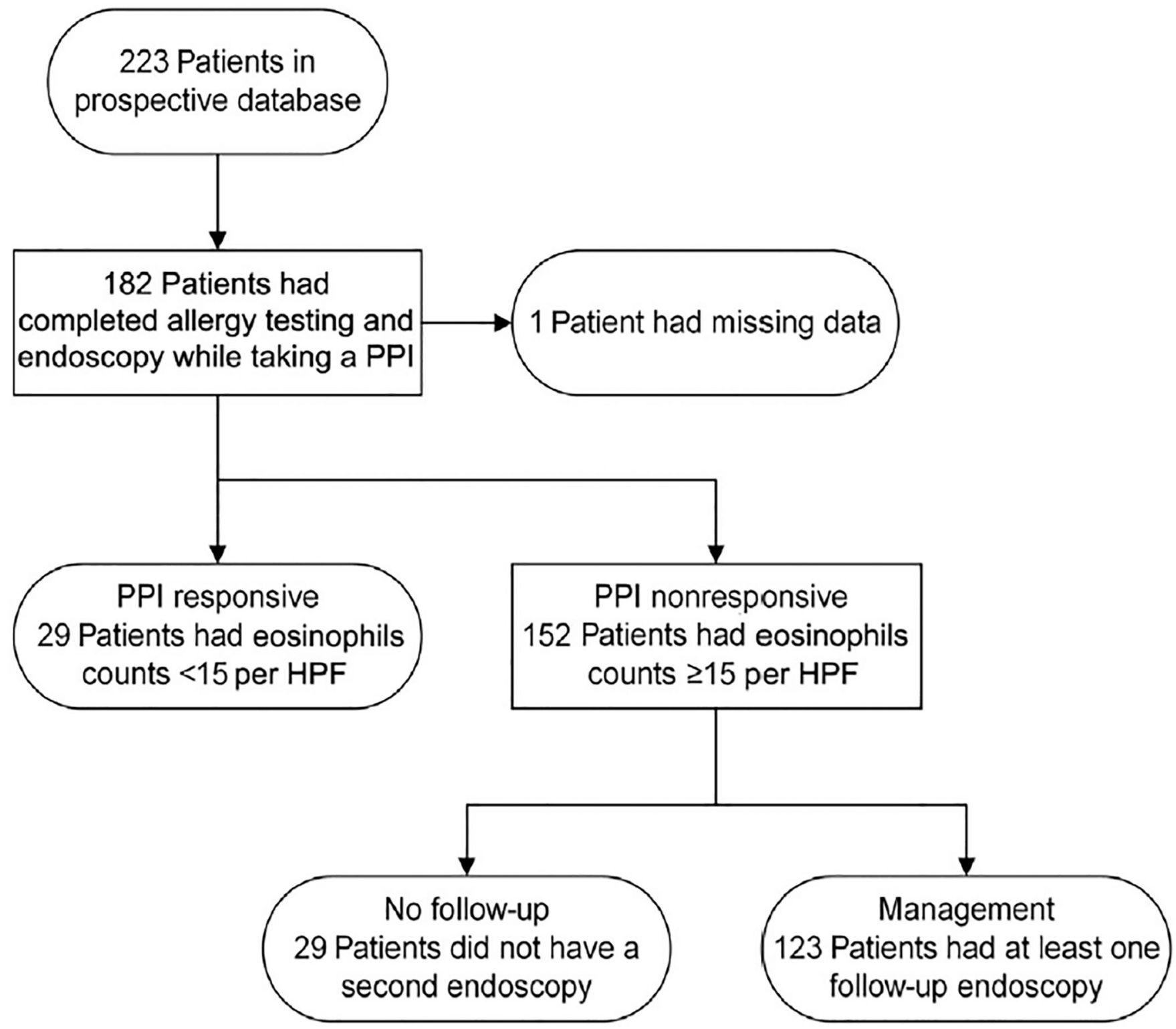

Figure 1.

Study population. Twenty-nine patients had proton pump inhibitor (PPI)-responsive eosinophilic esophagitis, and 123 patients with none-PPI-responsive eosinophilic esophagitis were further analyzed. 


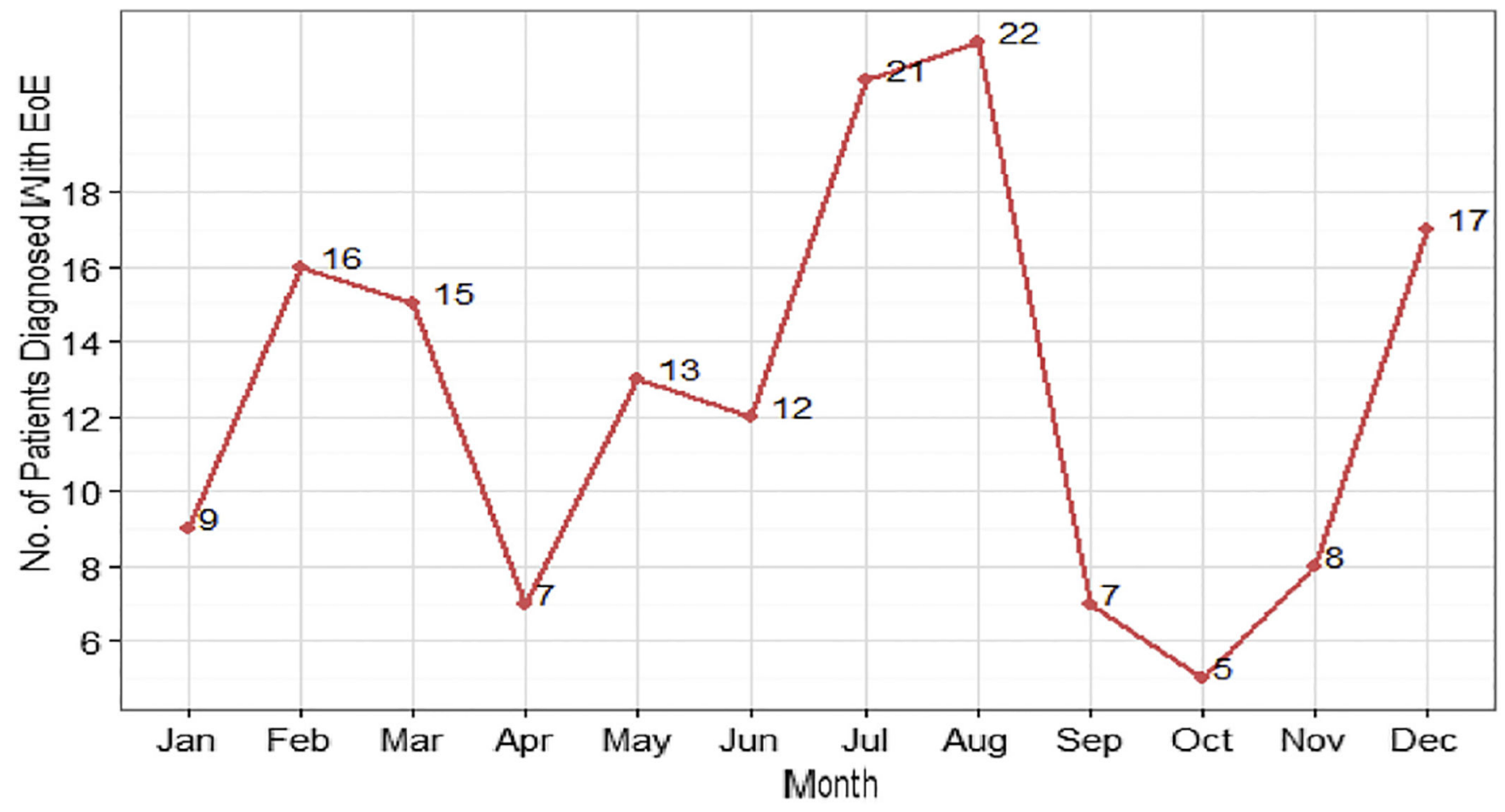

Figure 2.

Frequency of eosinophilic esophagitis (EoE) diagnosis based on month of year. Patients were more likely to have their conditions diagnosed during the months of July and August and least likely to have their conditions diagnosed during September, October, and November. 


\section{Table 1}

Patient Demographic Characteristics ${ }^{a}$

\begin{tabular}{|c|c|c|c|c|}
\hline Characteristic & Total $(\mathrm{N}=123)$ & Complete responders $(n=72)$ & Nonresponders $(\mathbf{n}=\mathbf{3 3})$ & $P$ value \\
\hline \multicolumn{5}{|l|}{ Sex } \\
\hline Female & $38(30.9)$ & $25(34.7)$ & $7(21.2)$ & .18 \\
\hline Male & $85(69.1)$ & $47(65.3)$ & $26(78.8)$ & \\
\hline \multicolumn{5}{|l|}{ Race } \\
\hline African American & $11(8.9)$ & $7(9.9)$ & $3(9.1)$ & .75 \\
\hline Asian & $1(0.8)$ & $1(1.4)$ & 0 & \\
\hline White & $105(86.1)$ & $61(85.9)$ & $28(84.8)$ & \\
\hline Hispanic & $1(0.8)$ & $1(1.4)$ & 0 & \\
\hline Multiple & $4(3.3)$ & $1(1.4)$ & $2(6.1)$ & \\
\hline \multicolumn{5}{|l|}{ Type of insurance } \\
\hline Medicaid/Medicare & $55(44.7)$ & $33(45.8)$ & $12(36.4)$ & .29 \\
\hline Private & $47(38.2)$ & $9(12.5)$ & $8(24.2)$ & \\
\hline Multiple & $21(17.1)$ & $30(41.7)$ & $13(39.4)$ & \\
\hline \multicolumn{5}{|l|}{ Counties (population) } \\
\hline Urban $(>65,000)$ & $73(59.3)$ & $43(59.7)$ & $19(57.6)$ & .84 \\
\hline Nonurban $(>20,000-64,999)$ & $26(21.1)$ & $16(22.2)$ & $9(27.3)$ & \\
\hline Rural $(<20,000)$ & $24(19.5)$ & $13(18.1)$ & $5(15.2)$ & \\
\hline \multicolumn{5}{|l|}{ No. of follow-up visits } \\
\hline 0 & 0 & 0 & 0 & .12 \\
\hline 1 & $11(8.9)$ & $4(5.6)$ & $5(15.2)$ & \\
\hline 2 & $25(20.3)$ & $13(18.1)$ & $9(27.3)$ & \\
\hline$\geq 3$ & $87(70.7)$ & $55(76.4)$ & $19(57.6)$ & \\
\hline No. follow-up visits, mean (range) & $4(2-6)$ & $5(3-8)$ & $3(2-4)$ & $<.001$ \\
\hline No. of endoscopies, mean (range) & $3.0(3.0-5.0)$ & $4.5(3.0-7.0)$ & $3.0(2.0-3.0)$ & $<.001$ \\
\hline Age of diagnosis EoE, mean (range), y & $8.0(3.0-11.0)$ & $7.0(3.0-10.2)$ & $10.0(4.0-13.0)$ & .18 \\
\hline
\end{tabular}

${ }^{a}$ Data are presented as number (percentage) of patients unless otherwise indicated. 
Table 2

Allergen Sensitization Profiles (Positive Skin Prick Test or IgE Test Results)

\begin{tabular}{|c|c|c|c|c|}
\hline \multirow[t]{2}{*}{ Variable } & \multicolumn{3}{|c|}{ No. $(\%)$ of patients with positive results } & \multirow[t]{2}{*}{$P$ value } \\
\hline & Total $(\mathrm{N}=123)$ & Complete responders $(n=72)$ & Nonresponders $(\mathbf{n}=\mathbf{3 3})$ & \\
\hline \multicolumn{5}{|l|}{ Allergen } \\
\hline Dust mites & $42(34.1)$ & $24(34.3)$ & $11(33.3)$ & $>.99$ \\
\hline Cat & $36(29.3)$ & $16(22.2)$ & $9(27.3)$ & .62 \\
\hline Dog & $22(17.9)$ & $11(15.3)$ & $7(21.2)$ & .58 \\
\hline Cockroach & $18(14.6)$ & $6(8.3)$ & $8(24.2)$ & .06 \\
\hline Molds & $35(28.4)$ & $16(22.2)$ & $14(42.4)$ & .06 \\
\hline Trees & $55(44.7)$ & $27(37.5)$ & $18(56.2)$ & .20 \\
\hline Grasses & $52(42.2)$ & $26(36.1)$ & $18(56.2)$ & .19 \\
\hline Weeds & $49(39.8)$ & $24(33.3)$ & $16(48.5)$ & .27 \\
\hline \multicolumn{5}{|c|}{ Allergen groups } \\
\hline Perennial & NA & $33(45.8)$ & $24(72.7)$ & .02 \\
\hline Seasonal & NA & $32(47.8)$ & $20(60.6)$ & .29 \\
\hline Molds & NA & $16(22.2)$ & $14(42.4)$ & .06 \\
\hline \multicolumn{5}{|c|}{ No. of allergen groups ${ }^{a}$} \\
\hline 0 & NA & $28(26.7)$ & $9(8.6)$ & .10 \\
\hline 1 & NA & $10(9.5)$ & $4(3.8)$ & \\
\hline 2 & NA & $11(10.5)$ & $1(0.9)$ & \\
\hline $3-5$ & NA & $12(11.4)$ & $11(10.5)$ & \\
\hline$>5$ & NA & $11(10.5)$ & $8(7.6)$ & \\
\hline
\end{tabular}

Abbreviation: NA, not applicable.

Boldface indicates significance.

${ }^{a}$ An allergen group consisted of positive test results to at least one allergen grouped by categories: dust mites, cat, dog, cockroach, molds, trees, grasses, and/or weeds. 
Table 3

Response Status to Management and by Age Group

\begin{tabular}{|c|c|c|c|}
\hline \multirow[t]{2}{*}{ Management type } & \multicolumn{2}{|l|}{ No. $(\%)$ of patients } & \multirow[t]{2}{*}{$P$ value } \\
\hline & Complete responders $(n=72)$ & Nonresponders $(n=33)$ & \\
\hline \multicolumn{4}{|l|}{ Management type } \\
\hline None & $1(1.4)$ & $0(0.0)$ & .03 \\
\hline Diet elimination & $32(44.4)$ & $19(57.6)$ & \\
\hline Swallowed corticosteroids & $21(29.2)$ & $2(6.1)$ & \\
\hline Diet elimination and corticosteroids & $18(25.0)$ & $12(36.3)$ & \\
\hline \multicolumn{4}{|c|}{ Diet elimination (alone or with swallowed corticosteroids) } \\
\hline Allergen specific elimination & $39(54.2)$ & $29(87.9)$ & .90 \\
\hline 6-Food elimination & $11(15.3)$ & $10(30.3)$ & \\
\hline Elemental & $1(1.4)$ & $1(3.0)$ & \\
\hline \multicolumn{4}{|l|}{ Age, y } \\
\hline $5(\mathrm{n}=52)$ & $32(61.5)$ & $12(36.4)$ & .049 \\
\hline $6 \mathrm{e} 11(\mathrm{n}=42)$ & $28(66.6)$ & $8(24.2)$ & \\
\hline $12(n=29)$ & $12(41.3)$ & $13(39.4)$ & \\
\hline
\end{tabular}


Table 4

Association of Perennial Allergen Sensitization, Age, and Response Status

\begin{tabular}{|c|c|c|c|}
\hline \multirow[t]{2}{*}{ Age Group and perennial allergen testing result } & \multicolumn{2}{|c|}{ No. $(\%)$ of tested patients } & \multirow[t]{2}{*}{ P value } \\
\hline & Complete responders & Nonresponders & \\
\hline \multicolumn{4}{|l|}{$<5$ years $(n=44)$} \\
\hline Positive & $15(46.9)$ & $6(50)$ & .99 \\
\hline Negative & $17(53.1)$ & $6(50)$ & \\
\hline \multicolumn{4}{|l|}{$6-11$ years $(n=36)$} \\
\hline Positive & $10(35.7)$ & $7(87.5)$ & .02 \\
\hline Negative & $18(64.3)$ & $1(12.5)$ & \\
\hline \multicolumn{4}{|l|}{$>12$ years $(n=25)$} \\
\hline Positive & $8(66.7)$ & $11(84.6)$ & .38 \\
\hline Negative & $4(33.3)$ & $2(15.4)$ & \\
\hline
\end{tabular}

Boldface indicates significance. 
Table 5

Associated Between Cockroach and Mold Sensitization and Response Status

\begin{tabular}{|c|c|c|c|c|c|c|}
\hline \multirow[t]{2}{*}{ Result } & \multicolumn{3}{|l|}{ Cockroach } & \multicolumn{3}{|l|}{ Mold } \\
\hline & Complete responders & Nonresponders & $P$ value & Complete responders & Nonresponders & $P$ value \\
\hline \multicolumn{7}{|l|}{ Total } \\
\hline Positive & $6(8.6)$ & $8(24.2)$ & .06 & $16(22.5)$ & $14(42.4)$ & .06 \\
\hline Negative & $64(91.4)$ & $25(75.8)$ & & $55(77.5)$ & $19(57.6)$ & \\
\hline \multicolumn{7}{|c|}{ Diet restriction } \\
\hline Positive & $4(12.9)$ & $1(5.3)$ & .64 & $9(28.1)$ & $6(31.6)$ & $>.99$ \\
\hline Negative & $27(87.1)$ & $18(94.7)$ & & $23(71.9)$ & $13(68.4)$ & \\
\hline \multicolumn{7}{|c|}{ Swallowed corticosteroids } \\
\hline Positive & $2(10.0)$ & $1(50.0)$ & .26 & $3(15.0)$ & $0(0)$ & $>.99$ \\
\hline Negative & $18(90.0)$ & $1(50.0)$ & & $17(85.0)$ & $2(100)$ & \\
\hline \multicolumn{7}{|c|}{ Diet and corticosteroids } \\
\hline Positive & $0(0)$ & $6(50.0)$ & .002 & $4(22.2)$ & $8(66.7)$ & .02 \\
\hline Negative & $18(100)$ & $6(50.0)$ & & $14(77.8)$ & $4(33.3)$ & \\
\hline
\end{tabular}

Boldface indicates significance. 